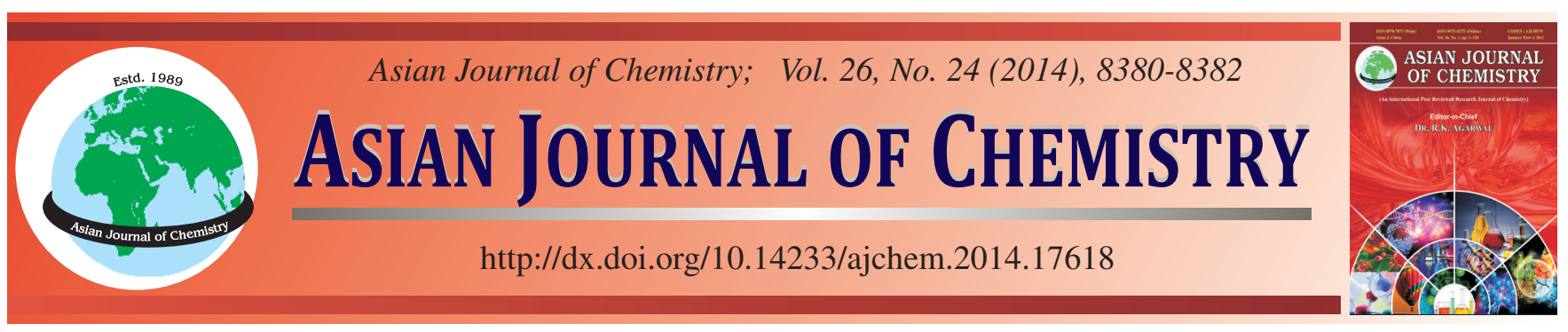

\title{
Magnesium Sulfate Promoted Efficient and Green Synthesis of Aminoalkyl, Amidoalkyl and Diarylmethane Derivatives
}

\section{S. Selva Ganesan* and G. Asaithampi}

Department of Chemistry, School of Chemical and Biotechnology, SASTRA University, Thanjavur-613 401 India

*Corresponding author: E-mail: selva@biotech.sastra.edu

\begin{abstract}
Under solvent-free condition, magnesium sulfate promoted the synthesis of substituted aminoalkyl naphthols, amidoalkyl naphthols and diarylmethane derivatives in excellent yield. Robust dehydrating nature and mild Lewis acidity of magnesium sulfate was exploited to carry out all the transformations.
\end{abstract}

Keywords: Green synthesis, Magnesium sulfate, One-pot synthesis, Solvent-free synthesis, Substituted naphthol.

\section{INTRODUCTION}

Substituted naphthol derivatives are interesting class of compounds exhibit wide spectrum of biological activity such as anticancer ${ }^{1}$, antiviral ${ }^{2}$, antitubercular ${ }^{3}$, antihypertensive ${ }^{4}$, anti-HIV ${ }^{5}$, etc. (Fig. 1). Assorted varieties of catalysts/reagents are reported in literature for substituted amidoalkyl and aminoalkyl naphthol synthesis ${ }^{6-9}$. However, several methods have limitations such as tedious preparation procedure of catalysts, corrosive and/or toxic nature of reagents, use of organic solvents, difficult product isolation processes, etc.

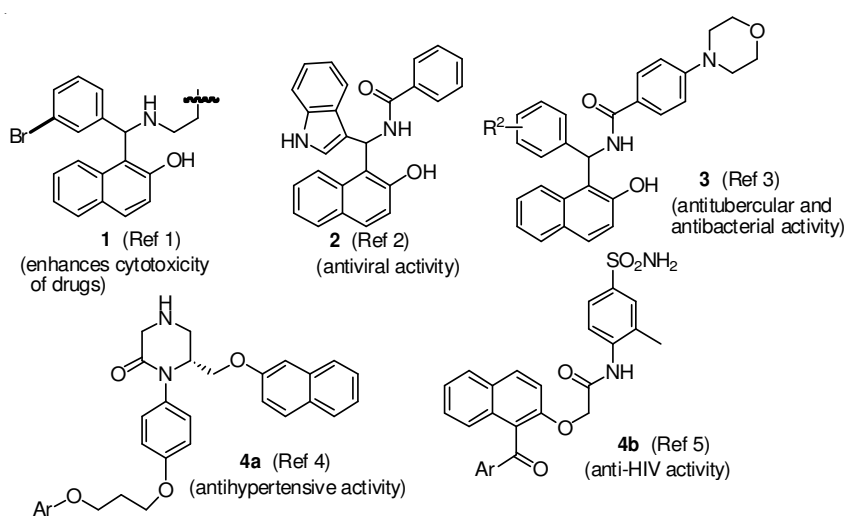

Fig. 1. Bioactive aminoalkyl and amidoalkyl naphthols

Anhydrous $\mathrm{MgSO}_{4}$ is commercially available, safe, nontoxic dehydrating agent with mild Lewis acidity. $\mathrm{MgSO}_{4}$ mediated dihydropyrimidin-2 $(1 H)$-ones ${ }^{10}$, phenazine and quinoxaline $^{11}, \beta$-nitroalkanols ${ }^{12}$, urea/acetamide derived substituted naphthol synthesis ${ }^{13}$ have been previously reported in literature. Multicomponent reactions offer a convenient way to synthesize highly functionalized molecules. Recently, several modern variants of multicomponent reaction have been reported in literature ${ }^{14 a-b}$. Solvent-free multicomponent reactions are known for their rapid conversion, energy efficient and environmentally benign nature ${ }^{14 c}$. In continuation of our efforts to devise efficient multicomponent reaction ${ }^{15 a-b}$, herein we report $\mathrm{MgSO}_{4}$ mediated solvent-free substituted naphthol synthesis.

\section{EXPERIMENTAL}

Anhydrous $\mathrm{MgSO}_{4}$ was purchased from HIMEDIA. Except benzaldehyde, all other reagents were used as such without further purification. Freshly distilled benzaldehyde was used for the reaction.

\section{General procedure for the magnesium sulfate promoted substituted naphthol synthesis}

Representative procedure for the synthesis of aminoalkyl naphthol: To a stirred mixture of $\beta$-naphthol ( $1 \mathrm{mmol}, 144 \mathrm{mg}$ ), anhydrous $\mathrm{MgSO}_{4}(0.5 \mathrm{mmol}, 60 \mathrm{mg})$ and $1.5 \mathrm{mmol}$ of amine in a $5 \mathrm{~mL}$ round bottom flask, $1.5 \mathrm{mmol}$ of aldehyde was added and the mixture was further stirred in an oil bath at RT or $60^{\circ} \mathrm{C}$ for required time. After completion of reaction, the reaction mixture was quenched with $5 \mathrm{~mL}$ of water, stirred and the aqueous layer was decanted and for $\mathbf{7}$ and $\mathbf{8}$, after quenching with $5 \mathrm{~mL}$ water, the reaction mixture was extracted with ethyl acetate $(2 \times$ $5 \mathrm{~mL}$ ). The organic layer was washed with water, brine and dried over anhydrous sodium sulfate.

1-(Morpholinomethyl)naphthalen-2-ol (6): Yield $=240$ mg (98 \%); White solid; m.p. $114-115^{\circ} \mathrm{C}$ (Lit. $\left.{ }^{16} 113-115^{\circ} \mathrm{C}\right)$; 
FT- IR $\left(\mathrm{KBr}, v_{\max }, \mathrm{cm}^{-1}\right): 3046,2975,2898,1621,1478,1265$, $815 \mathrm{~cm}^{-1} ;{ }^{1} \mathrm{H}$ NMR $\left(300 \mathrm{MHz}, \mathrm{CDCl}_{3}, \delta \mathrm{ppm}\right.$ ): 2.65 (br s, 4 H), $3.78(\mathrm{~s}, 4 \mathrm{H}), 4.15(\mathrm{~s}, 2 \mathrm{H}), 7.09(\mathrm{~d}, J=8.7 \mathrm{~Hz}, 1 \mathrm{H}), 7.25-$ $7.32(\mathrm{~m}, 1 \mathrm{H}), 7.42-7.47$ (m, 1H), 7.68-7.83 (m, 3H).

General procedure for the synthesis of amidoalkyl naphthol: To a stirred mixture of $\beta$-naphthol (1 mmol, $144 \mathrm{mg})$, anhydrous $\mathrm{MgSO}_{4}(2 \mathrm{mmol}, 241 \mathrm{mg})$ and benzamide $(1.5 \mathrm{mmol}, 181 \mathrm{mg})$ in a $5 \mathrm{~mL}$ round bottom flask, $1.2 \mathrm{mmol}$ of aldehyde was added and the mixture was further stirred and heated in an oil bath at $90{ }^{\circ} \mathrm{C}$ for $5 \mathrm{~h}$. After completion of the reaction, the reaction mixture was quenched with $5 \mathrm{~mL}$ of water, stirred and the aqueous layer was decanted. The gummy residue was stirred with ethanol:water mixture $(1: 3 \mathrm{v} / \mathrm{v}, 20 \mathrm{~mL})$, filtered, washed with $5 \mathrm{~mL}$ of cold ethanol and dried.

$N$-[(2-Hydroxynaphthalen-1-yl)(4-nitrophenyl)methyl]benzamide (16): Yield = $342 \mathrm{mg}(86 \%)$; Yellowish white crystals; m.p. $236-238{ }^{\circ} \mathrm{C}$ (Lit. ${ }^{17} 233-235{ }^{\circ} \mathrm{C}$ ); FT-IR (KBr, $\left.V_{\max }, \mathrm{cm}^{-1}\right): 3408,3260,1643,1517,1347,1057,865,810$, $706 ;{ }^{1} \mathrm{H}$ NMR (300 MHz, DMSO- $d_{6}, \delta$ ppm): 7.24 (d, $J=9.0$ $\mathrm{Hz}, 1 \mathrm{H}), 7.32$ (t, $J=7.2 \mathrm{~Hz}, 1 \mathrm{H}), 7.39(\mathrm{~d}, J=7.8 \mathrm{~Hz}, 1 \mathrm{H})$, 7.45-7.58 (m, $6 \mathrm{H}), 7.82-7.91(\mathrm{~m}, 4 \mathrm{H}), 8.06(\mathrm{~d}, J=8.4 \mathrm{~Hz}, 1$ H), $8.16(\mathrm{~d}, J=8.4 \mathrm{~Hz}, 2 \mathrm{H}), 9.08(\mathrm{~d}, J=7.8 \mathrm{~Hz}, 1 \mathrm{H}), 10.41$ (br s, $1 \mathrm{H}$ ).

General procedure for the synthesis of diarylmethanes: To a stirred mixture of $\beta$-naphthol ( $1 \mathrm{mmol}, 144$ $\mathrm{mg}$ ), anhydrous $\mathrm{MgSO}_{4}(1 \mathrm{mmol}, 120 \mathrm{mg}$ ) in a $5 \mathrm{~mL}$ round bottom flask, $2 \mathrm{mmol}$ of formaldehyde (37 \% soln.) and 1.2 mmol of $N, N$-dialkylaniline were subsequently added and the mixture was further stirred at room temperature for $15 \mathrm{~min}$. After completion, the reaction mixture was quenched with $5 \mathrm{~mL}$ of water, stirred and the aqueous layer was decanted. To the gummy solid, hexane $(2 \times 5 \mathrm{~mL})$ was added and the product was filtered and dried.

1-\{[4-(Dimethylamino)phenyl]methyl\}naphthalen-2-ol (17): Yield = $247 \mathrm{mg}(89 \%)$; Brown solid; m.p. $129-131^{\circ} \mathrm{C}$ (Lit. $\left.{ }^{18} 127-130{ }^{\circ} \mathrm{C}\right) ;{ }^{1} \mathrm{H}$ NMR $\left(300 \mathrm{MHz}, \mathrm{CDCl}_{3}, \delta \mathrm{ppm}\right): 2.87$ $(\mathrm{s}, 6 \mathrm{H}), 4.34(\mathrm{~s}, 2 \mathrm{H}), 5.10($ br s, $1 \mathrm{H}), 6.64(\mathrm{~d}, J=9.0 \mathrm{~Hz}$, 2H), 7.06-7.25 (m, 3H), 7.29-7.35 (m, 1H), 7.41-7.47 (m, 1H), $7.68(\mathrm{~d}, J=8.7 \mathrm{~Hz}, 1 \mathrm{H}), 7.78(\mathrm{~d}, J=8.1 \mathrm{~Hz}, 1 \mathrm{H}), 7.96(\mathrm{~d}, J=$ $8.4 \mathrm{~Hz}, 1 \mathrm{H})$.

\section{RESULTS AND DISCUSSION}

Initially, anhydrous $\mathrm{MgSO}_{4}$ mediated representative 1-(morpholin-4-ylmethyl)naphthalen-2-ol 6 synthesis was carried out under solvent-free condition. To our delight, with 0.5 equivalents of anhydrous $\mathrm{MgSO}_{4}$ itself the transformation was completed within 3 min in $98 \%$ yield (Scheme-I).

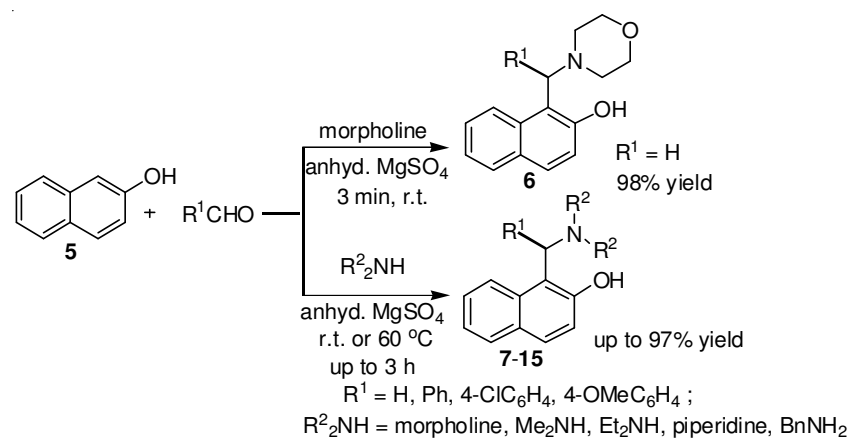

Scheme-I: Anhydrous $\mathrm{MgSO}_{4}$ mediated aminoalkyl naphthol synthesis

With 0.2 equivalents of anhydrous $\mathrm{MgSO}_{4}$, the reaction took 15 min to complete with a marginal decrease in the product yield to $95 \%$. Increasing the quantity of anhydrous $\mathrm{MgSO}_{4}$ to one equivalent reduced the reaction time to one minute with $98 \%$ yield. Half equivalent of anhydrous $\mathrm{MgSO}_{4}$ was chosen to carry out further transformations (Scheme-I, Table-1).

The aminoalkyl naphthols 6-8 synthesis in excellent yield at room temperature could be attributed to the high reactivity of formaldehyde (Scheme-I, Table-1, Entries 1, 2). With two equivalents of anhydrous $\mathrm{MgSO}_{4}$, both $\mathbf{7}$ and $\mathbf{8}$ were obtained within $1 \mathrm{~h}$. This reaction was found to be general for aldehydes with electron withdrawing (Table-1, Entries 3, 8) and electron donating substituents (Table-1, Entry 9). Aromatic aldehydes with electron withdrawing substituent gave better yield than aldehydes with electron donating substituent (Table-1, Entry 8 vs 9). Anhydrous $\mathrm{MgSO}_{4}$ mediated aminoalkyl naphthol synthesis was screened with various aliphatic cyclic and acyclic amines (Table-1, Entries 1-9). Secondary amines gave relatively better yield than that of primary amine (Table-1, Entry 1-4 vs 5). Both cyclic and acyclic amines gave the corresponding aminonaphthols in excellent yield (Table-1, Entry 2, 6). It is of interest to extend this methodology to the amidoalkyl naphthol and diarylmethane synthesis. After screening several conditions, it was found that reaction carried out at $90^{\circ} \mathrm{C}$ gave the expected product in good yield (SchemeII). Interestingly, reactions carried out in solvents such as ethanol, toluene and glycerol at $90{ }^{\circ} \mathrm{C}$ did not give expected product.

\begin{tabular}{ccccccccc}
\multicolumn{10}{c}{ TABLE-1 } \\
\hline Entry & $\mathrm{R}^{1}$ & $\mathrm{R}_{2}{ }_{2} \mathrm{NH}$ & Product & Temp $\left({ }^{\circ} \mathrm{C}\right)$ & Time $(\mathrm{h})$ & Yield $^{\mathrm{b}}(\%)$ & m.p. $\left({ }^{\circ} \mathrm{C}\right)$ & Reported m.p. $\left({ }^{\circ} \mathrm{C}\right)$ \\
\hline $1^{\mathrm{c}}$ & $\mathrm{H}$ & $\mathrm{Et}_{2} \mathrm{NH}$ & 7 & r.t. & 3 & 96 & - & - \\
$2^{\mathrm{c}}$ & $\mathrm{H}$ & $\mathrm{Me}_{2} \mathrm{NH}$ & 8 & r.t. & 3 & 97 & $57-59$ & $74-75^{19}$ \\
3 & $4-\mathrm{ClC}_{6} \mathrm{H}_{4}$ & $\mathrm{Me}_{2} \mathrm{NH}$ & 9 & 60 & 3 & 75 & $128-130$ & $128-130^{9}$ \\
4 & $\mathrm{C}_{6} \mathrm{H}_{5}$ & $\mathrm{Me}_{2} \mathrm{NH}$ & 10 & 60 & 3 & 85 & $162-164$ & $161-162^{20}$ \\
5 & $\mathrm{C}_{6} \mathrm{H}_{5}$ & $\mathrm{BnNH}_{2}$ & 11 & r.t. & 3 & $66(51)^{\mathrm{d}}$ & $141-142$ & $1433^{21}$ \\
6 & $\mathrm{C}_{6} \mathrm{H}_{5}$ & Morpholine & 12 & 60 & 1.5 & 91 & $174-176$ & $175-177^{15 \mathrm{~b}}$ \\
7 & $\mathrm{C}_{6} \mathrm{H}_{5}$ & Piperidine & 13 & 60 & 1.5 & 85 & $197-199$ & $195-196^{20}$ \\
8 & $4-\mathrm{ClC}_{6} \mathrm{H}_{4}$ & Morpholine & 14 & 60 & 3 & 87 & $127-129$ & $130-132^{22}$ \\
9 & $4-\mathrm{MeOC}_{6} \mathrm{H}_{4}$ & Morpholine & 15 & 60 & 3 & 69 & $124-125$ & $126^{23}$ \\
\hline
\end{tabular}

${ }^{a}$ To a finely ground mixture of anhydrous $\mathrm{MgSO}_{4}(0.5 \mathrm{mmol})$ and $\beta$-naphthol $(1 \mathrm{mmol})$, aldehyde $(1.5 \mathrm{mmol})$ and amine $(1.5 \mathrm{mmol})$ were added and stirred. In entries 3 and $\mathbf{8}$, aldehyde was ground along with anhydrous $\mathrm{MgSO}_{4}$ and $\beta$-naphthol. ${ }^{\text {b}}$ Yields are for the isolated products. ${ }^{\mathrm{C}} \mathrm{With} 2$ mmol of anhydrous $\mathrm{MgSO}_{4}$ the reaction completes within $1 \mathrm{~h}$. ${ }^{\mathrm{d}}$ Reaction was carried out at $60{ }^{\circ} \mathrm{C}$ for $3 \mathrm{~h}$ 

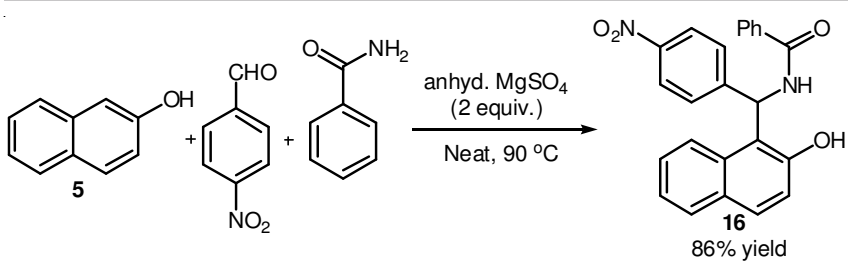

Scheme-II: Anhydrous $\mathrm{MgSO}_{4}$ mediated amidoalkyl naphthol synthesis

The formation of both amino/amidoalkyl naphthols can be explained based on the following mechanism (Scheme-III).

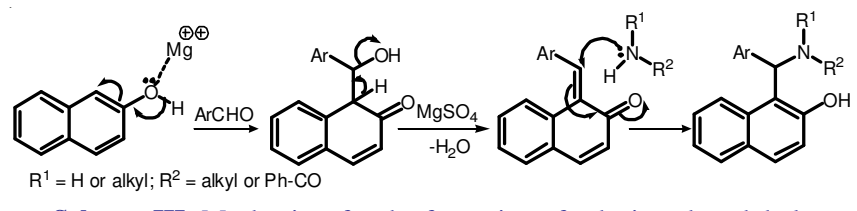

Scheme-III: Mechanism for the formation of substituted naphthols

We have also screened Friedel-Crafts reaction of $\beta$-naphthol with formaldehyde and $\mathrm{N}, \mathrm{N}$-dialkylaniline with one mmol of anhydrous $\mathrm{MgSO}_{4}$. To our delight, the reaction completed within $15 \mathrm{~min}$ at room temperature itself and the product $\mathbf{1 7}$ was obtained in $89 \%$ yield (Scheme-IV).

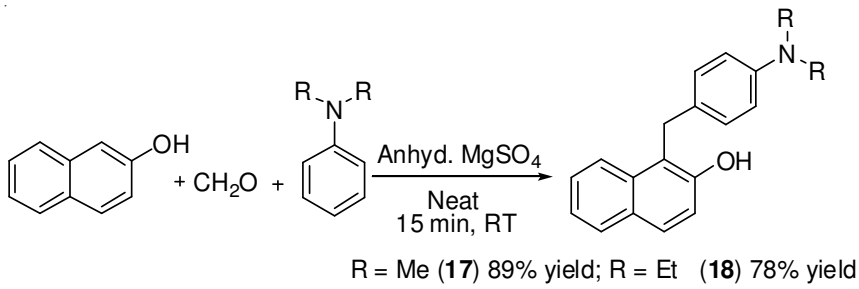

Scheme-IV: Anhydrous $\mathrm{MgSO}_{4}$ mediated diarylmethane synthesis

Moreover, the product can be isolated from the reaction medium by simple aqueous work-up. Previously available methods for diarylmethane synthesis use longer reaction time ${ }^{18}$. Anhydrous $\mathrm{MgSO}_{4}$ was identified as suitable reagent to carry out diarylmethane synthesis under mild condition. Investigations on synthetic utility of the magnesium sulfate in Mannichtype reactions are underway in our laboratory.

\section{Conclusion}

In summary, the mild, environmentally benign, non-toxic, readily available nature of anhydrous $\mathrm{MgSO}_{4}$ makes it a viable reagent for substituted naphthol synthesis. All the reactions were carried out under neat condition followed by simple isolation of the product from the reaction medium. In all transformations, products were obtained in good to excellent yield.

\section{ACKNOWLEDGEMENTS}

One of the authors, S. Selva Ganesan thanks DST for DSTFast Track grant (No: SR/FT/CS-09/2011). Thanks are also due to SASTRA University for providing lab space and NMR facility.

\section{REFERENCES}

1. N. Gyémánt, H. Engi, Z. Schelz, I. Szatmári, D. Tóth, F. Fülöp, J. Molnár and P.A.M. de Witte, Br. J. Cancer, 103, 178 (2010).

2. W.S.I. Abou-Elmagd and A.I. Hashem, Med. Chem. Res., 22, 2005 (2013).

3. A.P.G. Nikalje, M. Patel, Y. Ranade, R. Deshpande and D. Rajani, Der Pharm. Sin., 3, 462 (2012).

4. D.D. Holsworth, N.A. Powell, D.M. Downing, C. Cai, W.L. Cody, J.M. Ryan, R. Ostroski, M. Jalaie, J.W. Bryant and J.J. Edmunds, Bioorg. Med. Chem., 13, 2657 (2005).

5. X.-D. Ma, X. Zhang, H.-F. Dai, S.-Q. Yang, L.-M. Yang, S.-X. Gu, Y.-T. Zheng, Q.-Q. He and F.E. Chen, Bioorg. Med. Chem., 19, 4601 (2011).

6. M. Wang and Y. Liang, Monatsh. Chem., 142, 153 (2011).

7. S.R. Mistry, R.S. Joshi and K.C. Maheria, J. Chem. Sci., 123, 427 (2011).

8. B. Karmakar and J. Banerji, Tetrahedron Lett., 52, 4957 (2011).

9. A. Kumar, M.K. Gupta and M. Kumar, Tetrahedron Lett., 51, 1582 (2010).

10. D.M. Pore, U.V. Desai, T.S. Thopate and P.P. Wadgaonkar, Aust. J. Chem., 60, 435 (2007).

11. B. Karami and S. Khodabakhshi, J. Serb. Chem. Soc., 76, 1191 (2011).

12. P.B. Kisanga and J.G. Verkade, J. Org. Chem., 64, 4298 (1999).

13. K.C. Ashalu and J.N. Rao, J. Chem. Pharm. Res., 5, 44 (2013).

14. (a) N. Isambert, M.M.S. Duque, J.-C. Plaquevent, Y. Génisson, J. Rodriguez and T. Constantieux, Chem. Soc. Rev., 40, 1347 (2011); (b) C. de Graaff, E. Ruijter and R.V.A. Orru, Chem. Soc. Rev., 41, 3969 (2012); (c) M.S. Singh and S. Chowdhury, RSC Adv., 2, 4547 (2012).

15. (a) S.S. Ganesan and A. Ganesan, Tetrahedron Lett., 55, 694 (2014); (b) S.S. Ganesan, N. Rajendran, S. Sundarakumar, A. Ganesan and B. Pemiah, Synthesis, 1564 (2013).

16. K.-W. Chi, Y.S. Ahn, K.T. Shim, T.H. Park and J.S. Ahn, Bull. Korean Chem. Soc., 20, 973 (1999).

17. A. Khazaei, M.A. Zolfigol, A.R. Moosavi-Zare, F. Abi, A. Zare, H. Kaveh, V. Khakyzadeh, M. Kazem-Rostami, A. Parhami and H. Torabi-Monfared, Tetrahedron, 69, 212 (2013).

18. A. Kumar, M. Kumar and M.K. Gupta, Tetrahedron Lett., 50, 7024 (2009).

19. A. Bladé-Font and T.M. Rocabayera, J. Chem. Soc. Perkin Trans. I, 841 (1982).

20. M. Periasamy, S. Anwar and M.N. Reddy, Indian J. Chem., 48B, 1261 (2009).

21. F.E. Ray and W.R. Haefele, J. Am. Chem. Soc., 60, 36 (1938).

22. C. Mukhopadhyay, S. Rana and R.J. Butcher, Synth. Commun., 42, 3077 (2012).

23. S. Seshadri, A.L. Cherian and P.Y. Pandit, Indian J. Chem., 7, 1080 (1969). 